\title{
Sunitinib in combination with docetaxel in patients with advanced solid tumors: a phase I dose-escalation study
}

\author{
Francisco Robert • Alan Sandler • Joan H. Schiller • \\ Glenn Liu • Karen Harper • Lev Verkh • Xin Huang • \\ Jennifer Ilagan $\cdot$ Lesley Tye $\cdot$ Richard Chao $\cdot$ Anne M. Traynor
}

Received: 9 June 2009/Accepted: 7 December 2009/Published online: 31 December 2009

(C) The Author(s) 2009. This article is published with open access at Springerlink.com

\begin{abstract}
Purpose Sunitinib in combination with docetaxel enhances antitumor activity in xenograft models of human breast and non-small cell lung cancer. We assessed the maximum tolerated doses (MTDs), safety, pharmacokinetic profiles, and preliminary efficacy of sunitinib plus docetaxel in patients with advanced solid tumors.

Methods In this phase I study, successive patient cohorts received sunitinib $25,37.5$, or $50 \mathrm{mg} /$ day for 4 weeks of a 6-week cycle (Schedule 4/2, 4 weeks on, 2 weeks off) or for 2 weeks of a 3-week cycle (Schedule 2/1, 2 weeks on, 1 week off) with docetaxel 60 or $75 \mathrm{mg} / \mathrm{m}^{2}$ IV q21d to determine the MTDs of this treatment combination.

Results Fifty patients enrolled: 10 on Schedule $4 / 2$ and 40 on Schedule 2/1. MTDs were established as sunitinib $25 \mathrm{mg}$ on Schedule $4 / 2$ with docetaxel $60 \mathrm{mg} / \mathrm{m}^{2} \mathrm{q} 21 \mathrm{~d}$, and as sunitinib $37.5 \mathrm{mg}$ on Schedule $2 / 1$ with docetaxel $75 \mathrm{mg} / \mathrm{m}^{2} \mathrm{q} 21 \mathrm{~d}$. On Schedule $2 / 1$, the most frequent dose-
\end{abstract}

F. Robert $(\bowtie) \cdot$ K. Harper

University of Alabama at Birmingham,

Comprehensive Cancer Center, Birmingham, AL, USA

e-mail: pacorobertuab@cs.com

A. Sandler

Oregon Health \& Science University, Portland, OR, USA

J. H. Schiller

University of Texas Southwestern,

Division of Hematology and Oncology, Dallas, TX, USA

G. Liu - A. M. Traynor

University of Wisconsin Carbone Cancer Center,

Madison, WI, USA

L. Verkh $\cdot$ X. Huang $\cdot$ J. Ilagan $\cdot$ L. Tye $\cdot$ R. Chao

Pfizer Inc, Global Research and Development,

La Jolla, CA, USA limiting toxicity was neutropenia ( \pm fever; grade $[\mathrm{G}] 3 / 4$, $n=5$ ) and the most common G3/4 non-hematologic adverse event (AE) was fatigue (G3, $n=8)$. Hematologic AEs were managed with growth factor support in 11 of 23 $(48 \%)$ patients treated at Schedule 2/1 MTD. Three patients achieved a partial response at the Schedule 2/1 MTD. There were no pharmacokinetic drug-drug interactions with either schedule.

Conclusions Oral sunitinib $37.5 \mathrm{mg} /$ day on Schedule 2/1 with docetaxel $75 \mathrm{mg} / \mathrm{m}^{2}$ IV q21d is a clinically feasible regimen with a manageable safety profile, no pharmacokinetic drug-drug interactions, and shows antitumor activity in patients with advanced solid tumors.

Keywords Sunitinib - Docetaxel - Solid tumors .

Phase I · NSCLC · Antiangiogenesis

\section{Introduction}

Advances in the molecular biology of solid malignancies have established the critical role of tumor angiogenesis and the multiple signaling pathways involved in tumor development. Specifically, inhibition of the vascular endothelial growth factor (VEGF) pathway has been shown to improve clinical efficacy outcomes in patients with a variety of cancers [1-5]. There is interest in assessing the efficacy and safety of targeted agents given in combination with chemotherapy, including in patients with treatment-refractory cancers.

Docetaxel (Taxotere ${ }^{\circledR}$, Sanofi Aventis, US) is an effective anticancer therapy which stabilizes microtubules, leading to the formation of abnormal microtubule bundles that prevent mitotic processes [6, 7]. Its major dose-limiting toxicity (DLT) is reversible myelosuppression. In the 
US, docetaxel is indicated both as a single agent and in combination with other agents for various solid tumors including non-small cell lung cancer (NSCLC) and breast cancer [7].

Sunitinib malate (SUTENT ${ }^{\circledR}$, Pfizer Inc. US) is an oral multitargeted tyrosine kinase inhibitor (TKI), approved internationally for use in advanced renal cell carcinoma (RCC) and imatinib-resistant or -intolerant gastrointestinal stromal tumor (GIST), based on its demonstrated clinical activity and tolerability profile [8-10]. Sunitinib inhibits VEGF and platelet-derived growth factor (PDGF) receptor subtypes, stem cell factor receptor (KIT), FMS-like tyrosine kinase (FLT3), glial cell line-derived neurotrophic factor (REarranged during Transfection [RET]), and colony-stimulating factor 1 receptor (CSF-1R) [11-16]. Sunitinib has also shown clinically relevant antitumor activity in patients with other types of advanced solid tumors in phase I and phase II trials, including breast cancer, NSCLC, and neuroendocrine tumor [16-20]. Common drug-related toxicities associated with sunitinib are typically grade 1 or 2 in severity and are generally constitutional (fatigue, anorexia, headache), gastrointestinal (diarrhea, nausea, stomatitis, dyspepsia, vomiting, mucosal inflammation, constipation), or cutaneous (skin discoloration, rash, hand-foot syndrome, hair color changes) [16].

When given in combination, sunitinib enhances the antitumor activity of docetaxel in nonclinical studies. In H460 mouse xenograft models of NSCLC and MX-1 mouse xenograft models of breast cancer, the addition of sunitinib to docetaxel leads to significant delay of tumor regrowth compared with docetaxel alone [21, 22]. These data suggest that the combination of sunitinib with docetaxel may result in greater efficacy than docetaxel alone.

This phase I dose-finding study investigated the safety, pharmacokinetics (PK), and efficacy of sunitinib in combination with docetaxel in patients with advanced solid tumors.

\section{Materials and methods}

\section{Patient eligibility}

Male and female patients who were 18 years of age or older, had histologically proven advanced solid tumors for which curative therapy was not available, and were considered eligible for treatment with standard doses of singleagent docetaxel were recruited. All patients provided written and informed consent. Other key inclusion criteria included (a) Eastern Cooperative Oncology Group (ECOG) performance status of 0 or 1 ; (b) resolution of all acute toxic effects of prior chemotherapy, radiotherapy, or surgical procedure to National Cancer Institute Common
Terminology Criteria for Adverse Events (NCI CTCAE) grade $\leq 1$; (c) adequate hematologic parameters (absolute neutrophil count $[\mathrm{ANC}] \geq 1,500 / \mu \mathrm{L}$; platelets $\geq 100,000 /$ $\mu \mathrm{L}$; hemoglobin $\geq 9 \mathrm{~g} / \mathrm{dL}$ ) and hepatic, renal, and cardiac function, including left ventricular ejection fraction (LVEF) $\geq 50 \%$ without the support of cardiotropic agents.

Exclusion criteria included (a) prior treatment with highdose chemotherapy requiring stem cell rescue or prior irradiation to $\geq 25 \%$ of the bone marrow; (b) surgery, systemic therapy or any investigational agent within 4 weeks prior to starting study treatment; (c) extensive prior anthracycline or anthracenedione exposure (i.e. cumulative doxorubicin exposure $>300 \mathrm{mg} / \mathrm{m}^{2}$, epirubicin exposure $>900 \mathrm{mg} / \mathrm{m}^{2}$, mitoxanthrone exposure $>120 \mathrm{mg} /$ $\mathrm{m}^{2}$, doxorubicin liposome injection exposure $>550 \mathrm{mg} /$ $\mathrm{m}^{2}$ ); (d) centrally located lung lesions (unless irradiated with $\geq 30$ Gy $>2$ weeks prior to starting study treatment); (e) NCI CTCAE grade 3 hemorrhage within 4 weeks of study entry, significant hemoptysis, or grade $\geq 2$ neuropathy or edema; (f) diagnosis of a second malignancy within the last 5 years, except for adequately treated basal or squamous cell skin cancer, localized prostate cancer, or in situ bladder or cervical cancer; (g) known brain metastases, spinal cord compression or carcinomatous meningitis, or new evidence of brain or leptomeningeal disease; (h) severe/unstable angina, symptomatic congestive heart failure, cerebrovascular accident or transient ischemic attack within 12 months of study entry or ongoing cardiac dysrhythmias (grade $\geq 2$ ), atrial fibrillation or QTc interval prolongation; (i) history of severe hypersensitivity reaction to docetaxel or other drugs formulated with polysorbate 80 . Patients who were pregnant or breastfeeding were also excluded.

\section{Study design and treatment}

In this phase I, open-label, multicenter, non-randomized, dose-finding study, successive cohorts of patients received IV docetaxel q21d in combination with escalating daily doses of oral sunitinib.

Sunitinib was administered using one of two dosing schedules over approximately 18 weeks: 4 consecutive weeks of once-daily treatment followed by 2 weeks off treatment (Schedule 4/2) in three repeated 6-week cycles, or 2 consecutive weeks of once-daily treatment followed by 1 week off treatment (Schedule 2/1) in six repeated 3week cycles. To enable sampling for PK profiles, on Schedule $4 / 2$, patients were administered sunitinib once daily on days $4-31$ in cycle 1 . Patients were administered sunitinib daily on days 1-28 in subsequent cycles. On Schedule 2/1, patients were administered sunitinib daily on days 1-14 with the exception of patients undergoing fullprofile PK assessments; these patients were administered 
sunitinib on days 3-16. In subsequent cycles, sunitinib was administered daily on days 1-14. To ensure patient safety, the starting dose level was sunitinib at $25 \mathrm{mg} /$ day $(50 \%$ of its previously determined maximum tolerated dose [MTD] as monotherapy on Schedule 4/2) with docetaxel at $60 \mathrm{mg}$ / $\mathrm{m}^{2} \mathrm{q} 21 \mathrm{~d}$ (the lowest dose recommended in the United States package insert). MTD was defined as the highest dose at which $0 / 3$ or $1 / 6$ patients experienced a DLT (protocoldefined as grade 3 or 4 non-hematologic toxicity lasting $\geq 7$ days, or grade 4 neutropenia $\geq 7$ days, febrile neutropenia [fever $>38.5^{\circ} \mathrm{C}$ for $\geq 24 \mathrm{~h}$ ], neutropenic infection, and/or grade $\geq 3$ thrombocytopenia with bleeding or lasting $\geq 7$ days) during the first 31 or 21 days of cycle 1 (Schedules 4/2 and 2/1, respectively), with the next highest dose having $\geq 2 / 3$ or $\geq 2 / 6$ patients experiencing a DLT. Additional patients were enrolled at the MTD to further characterize safety and tolerability at this dose level.

Escalating doses of sunitinib and docetaxel were first studied on Schedule 4/2, starting at dose level 0 (Table 1). Following determination of Schedule 4/2 MTD, subsequent patients were enrolled onto Schedule 2/1, starting at the Schedule 4/2 MTD. Dose escalation and de-escalation occurred as detailed in Table 1 in order to determine the MTD on Schedule 2/1. Initial cohorts of 3 patients were enrolled onto Schedule 4/2, and any cohort was expanded to 6 patients if a DLT was observed. An additional 3 patients could be included at specific dose levels to further explore the observed toxicity profile.
Patients were treated for the entire study period unless there was disease progression, lack of tolerance, or withdrawal of consent. Dose reductions by one or two dose levels of either or both study drugs were permitted after completion of the DLT observation period. After completing the study period, patients who were receiving clinical benefit were offered participation in an extendeduse protocol of single-agent sunitinib.

The study was performed with institutional ethics committee approval, and in accordance with International Conference on Harmonization Good Clinical Practice guidelines, the Declaration of Helsinki (1996 Version), and applicable local regulatory requirements and laws.

\section{Study endpoints and assessments}

The primary objective of this trial was to assess the MTD and overall safety of sunitinib in combination with docetaxel when sunitinib was administered on Schedule 4/2 or $2 / 1$ in patients with solid tumors. Secondary objectives were to evaluate PK profiles and the efficacy of this treatment combination.

Safety was assessed by recording adverse events (AEs) documented from the first day of study medication (docetaxel or sunitinib) and graded using NCI CTCAE, version 3.0. Other safety assessments included urinalysis at screening, hematology and blood chemistry parameters, and physical examinations. Twelve-lead electrocardiograms

Table 1 Sunitinib and docetaxel dosing schedules, and dose-limiting toxicities

\begin{tabular}{|c|c|c|c|c|}
\hline & $\begin{array}{l}\text { Docetaxel (every } 21 \text { days) } \\
\left(\mathrm{mg} / \mathrm{m}^{2}\right)\end{array}$ & $\begin{array}{l}\text { Sunitinib (once-daily dose) } \\
\text { (mg) }\end{array}$ & Patients $(N)$ & DLTs $(n / N)$ \\
\hline \multicolumn{5}{|l|}{ Schedule $4 / 2$} \\
\hline Dose level $0^{\mathrm{a}}$ & 60 & 25 & 4 & None \\
\hline Dose level 1 & 60 & 37.5 & 6 & $\begin{array}{l}\text { Grade } 3 \text { muscular weakness }(n=1) \\
\text { Grade } 3 \text { febrile neutropenia }(n=1)\end{array}$ \\
\hline \multicolumn{5}{|l|}{ Schedule $2 / 1^{\mathrm{b}}$} \\
\hline Dose level $0^{\mathrm{a}}$ & 60 & 25 & 9 & $\begin{array}{l}\text { Grade } 4 \text { febrile neutropenia }(n=1) \\
\text { Grade } 4 \text { neutropenia }(n=1)\end{array}$ \\
\hline Dose level 1 & 60 & 37.5 & 3 & None \\
\hline Dose level 2 & 60 & 50 & 3 & None \\
\hline Dose level 3a & 75 & 50 & 2 & $\begin{array}{l}\text { Grade } 3 \text { febrile neutropenia }(n=1) \\
\text { Grade } 4 \text { neutropenia }(n=1)\end{array}$ \\
\hline Dose level $3 b^{c}$ & 75 & 37.5 & 23 & $\begin{array}{l}\text { Grade } 3 \text { gastrointestinal hemorrhage }(n=1) \\
\text { Grade } 4 \text { febrile neutropenia }(n=1)\end{array}$ \\
\hline
\end{tabular}

MTDs were Schedule 4/2: sunitinib $25 \mathrm{mg} / \mathrm{day}+$ docetaxel $60 \mathrm{mg} / \mathrm{m}^{2} \mathrm{q} 21 \mathrm{~d}$; Schedule 2/1: $37.5 \mathrm{mg} / \mathrm{day}+$ docetaxel $75 \mathrm{mg} / \mathrm{m}^{2} \mathrm{q} 21 \mathrm{~d}$

${ }^{\text {a }}$ Initial dose used

b Following completion of Schedule 4/2 dose determination (18 weeks on study), subsequent patients were enrolled onto Schedule 2/1, starting at Schedule 4/2 MTD

c Six patients were originally enrolled at this dose level with one DLT (grade 3 gastrointestinal hemorrhage) observed. The cohort was expanded to include 17 additional patients to further characterize the safety and tolerability of this dose level 
(ECG) and multigated acquisition (MUGA) scans were performed at screening and during treatment (cycles 1 and 3 , respectively for Schedule 4/2, and cycles 2 and 6 , respectively for Schedule 2/1).

Objective tumor response was assessed in patients with measurable disease according to Response Evaluation Criteria in Solid Tumors (RECIST) [23]. Radiologic tumor assessments were performed at screening, during treatment (during cycles 1 and 2 for Schedule 4/2, and cycles 2 and 4 for Schedule 2/1), at the end of the dosing period (if not performed within the previous 6 weeks), whenever disease progression was suspected and to confirm response (at least 4 weeks after initial evidence of response).

Full PK profiles for docetaxel and sunitinib were obtained for all patients on Schedule 4/2 and those patients enrolled on the MTD expansion cohort on Schedule 2/1. PK parameters for sunitinib, its primary metabolite (SU12662), total drug (sunitinib + SU12662), and docetaxel are reported as well as trough levels. Full PK profiles for docetaxel were obtained on days 1 and 22 of cycle 1 on Schedule 4/2 and on day 1 of cycles 1 and 2 on Schedule 2/1, using blood samples collected predose and $0.5,1,1.5,2,3,4,6,8,12$, and $24 \mathrm{~h}$ post-docetaxel dose. Docetaxel PK parameters were analyzed at Covance Laboratories (Madison, WI) using a validated liquid chromatographic-tandem mass spectrometric method in accordance with Covance's SOPs. Full PK profiles for sunitinib and SU12662 were obtained on days 18 and 22 on Schedule 4/2 and on day 3 of cycle 1 , and day 1 of cycle 2 on Schedule 2/1. Blood samples were collected pre-dose, and 1, 2, 4, 6, 8, 12, and $24 \mathrm{~h}$ post-sunitinib dose. Additional trough blood samples were collected for patients on Schedule 4/2 on cycles $2 / 3$ days 1 and 28 (day 31 of cycle 1 only) and on Schedule 2/1 on cycles 1-6 day 1 and day 14 of cycle 1 . Sunitinib PK parameters were analyzed at Bioanalytical Systems Inc (BASi, West Lafayette, IN) using a validated liquid chromatographic-tandem mass spectrometric method in accordance with BASi's standard operating procedures (SOPs).

\section{Statistical methods}

Maximum enrollment into the trial was dependent upon the observed safety profile, which determined the number of patients per dose level and number of dose escalations. The populations for safety analyses included all patients who had taken at least one dose of study medication. Efficacy analyses were performed on patients with measurable disease at baseline who received at least one dose of sunitinib and had a response assessment made by the investigator.

Descriptive statistics were used to summarize all patient characteristics, safety parameters, efficacy endpoints, and PK parameters. PK parameters were calculated for each subject by noncompartmental analysis using WinNonlin Version 4.1a. Samples below the limit of quantitation were included as zero. If pre-dose concentrations of a study drug or metabolite for an individual were $>5 \%$ of $C_{\max }$, a dose correction was made. Only patients with paired observations at each dose level were included in descriptive statistics for PK profiles of sunitinib, SU12662, total drug, and docetaxel, and for comparison of PK parameters when sunitinib or docetaxel was administered alone or in combination. Trough data are reported for all patients with trough observations.

\section{Results}

Patient characteristics

In total, 50 patients were enrolled into the trial; 10 patients and 40 patients received sunitinib on Schedule 4/2 and Schedule 2/ 1 , respectively. Patient characteristics at baseline are summarized in Table 2. NSCLC (Schedule 4/2: $n=1,10 \%$; Schedule 2/1: $n=17,43 \%$ ) and RCC (Schedule 4/2: $n=7$, $70 \%$; Schedule $2 / 1: n=3,8 \%$ ) were the most common tumor types. All patients had undergone previous cancer-related surgery, and most had received previous systemic therapy (Schedule 4/2: $n=10,100 \%$; Schedule 2/1 $n=32,80 \%$ ). Five $(50 \%)$ and $11(28 \%)$ patients had undergone previous radiotherapy on Schedules $4 / 2$ and $2 / 1$, respectively.

On Schedule 4/2, the median number of treatment cycles started was two (range $1-3)$. Thirty percent $(n=3)$ of sunitinib treatment interruptions were due to AEs (Table 3). Of the 10 patients on Schedule 4/2, 5, 2, and 3 patients received 1,2 , and 3 cycles of sunitinib treatment, respectively. On Schedule 2/1, the median number of treatment cycles started was four (range 1-6). The $28 \%$ $(n=11)$ of sunitinib treatment interruptions were all due to AEs (Table 3). Of the 40 patients on Schedule 2/1, 8, 7, and 2 patients started 1,2 , and 3 cycles of sunitinib treatment, respectively, and 8, 3, and 12 patients started 4, 5, and 6 cycles of sunitinib treatment, respectively.

Six patients $(60 \%)$ discontinued treatment on Schedule 4/2 due to AEs, including dyspnea; muscular weakness and hypoesthesia; infection; atrial fibrillation and thrombosis; obstructive airways disorder; and pain, nausea, and vomiting in 1 patient each. Five patients $(13 \%)$ discontinued treatment on Schedule $2 / 1$ due to AEs, which included disease progression (3 patients); pyrexia and infection (1 patient); and fatigue, anorexia, leukopenia, neutropenia, dehydration, and diarrhea (1 patient).

Safety and tolerability

Schedule $4 / 2$

Determination of MTD MTD was determined as sunitinib $25 \mathrm{mg} /$ day on Schedule 4/2 plus docetaxel $60 \mathrm{mg} / \mathrm{m}^{2} \mathrm{q} 21 \mathrm{~d}$ 
Table 2 Patient characteristics at baseline

\begin{tabular}{|c|c|c|c|}
\hline & \multirow[t]{2}{*}{ Schedule $4 / 2(N=10)$} & \multicolumn{2}{|l|}{ Schedule $2 / 1$} \\
\hline & & All patients $(N=40)$ & $\operatorname{MTD}^{\mathrm{a}}$ only $(n=23)$ \\
\hline \multicolumn{4}{|l|}{ Age in years } \\
\hline Median (range) & $57(46-72)$ & $56(26-74)$ & $55(37-73)$ \\
\hline$<65, n(\%)$ & $7(70)$ & $33(83)$ & $18(78)$ \\
\hline$\geq 65, n(\%)$ & $3(30)$ & $7(18)$ & $5(22)$ \\
\hline \multicolumn{4}{|l|}{ Sex, $n(\%)$} \\
\hline Male & $8(80)$ & $20(50)$ & $7(30)$ \\
\hline Female & $2(20)$ & $20(50)$ & $16(70)$ \\
\hline \multicolumn{4}{|l|}{ ECOG performance status, $n(\%)$} \\
\hline 0 & $2(20)$ & $8(20)$ & $4(17)$ \\
\hline 1 & $8(80)$ & $32(80)$ & $19(83)$ \\
\hline \multicolumn{4}{|l|}{ Primary tumor types, $n(\%)$} \\
\hline $\mathrm{RCC}$ & $7(70)$ & $3(8)$ & 0 \\
\hline NSCLC & $1(10)$ & $17(43)$ & $11(48)$ \\
\hline Adenocarcinoma & 0 & $7(18)$ & $3(13)$ \\
\hline Squamous cell carcinoma & 0 & $3(8)$ & $2(9)$ \\
\hline Bronchioloalveolar carcinoma & 0 & $1(3)$ & $1(4)$ \\
\hline Other/NOS & $1(10)$ & $6(15)$ & $5(22)$ \\
\hline Other tumor type ${ }^{b}$ & $2(20)$ & $20(50)$ & $12(52)$ \\
\hline Previous cancer-related surgery & $10(100)$ & $40(100)$ & $23(100)$ \\
\hline \multicolumn{4}{|l|}{ Outcome } \\
\hline Partial/complete resection & $1(10) / 6(60)$ & $2(5) / 19(48)$ & $1(4) / 9(39)$ \\
\hline Not applicable & $3(30)$ & $19(48)$ & $13(57)$ \\
\hline Previous radiotherapy & $5(50)$ & $11(28)$ & $6(26)$ \\
\hline Previous systemic therapy & $10(100)$ & $32(80)$ & $17(74)$ \\
\hline \multicolumn{4}{|l|}{ Number prior systemic therapies } \\
\hline 1 & $2(20)$ & $6(15)$ & $3(13)$ \\
\hline$\geq 2$ & $8(80)$ & $26(65)$ & $14(61)$ \\
\hline
\end{tabular}

ECOG Eastern cooperative oncology group, NOS not otherwise specified, NSCLC non-small cell lung carcinoma, $R C C$ renal cell carcinoma

a $2 / 1 \mathrm{MTD}=$ sunitinib $37.5 \mathrm{mg} / \mathrm{day}+$ docetaxel $75 \mathrm{mg} / \mathrm{m}^{2} \mathrm{q} 21 \mathrm{~d}$

b Other primary tumor type includes: esophageal carcinoma, metastatic melanoma, adenocystic-salivary gland (metastatic), carcinoid tumor of colon and appendix, ductal carcinoma in situ (breast), gastric adenocarcinoma, malignant mesothelioma, metastatic osteosarcoma, metastatic adenocystic carcinoma (vulva), metastatic pulmonary carcinoid tumor, metastatic soft tissue sarcoma, neuroendocrine, pancreas, prostate, rectal carcinoma, retroperitoneal leiomyosarcoma, small cell lung cancer, and well-differentiated neuroendocrine carcinoma

(dose level $0, n=4$ ); no DLTs were observed at this dose level. DLTs at dose level 1 (sunitinib $37.5 \mathrm{mg} /$ day, docetaxel $60 \mathrm{mg} / \mathrm{m}^{2} \mathrm{q} 21 \mathrm{~d}, n=6$ ) were grade 3 muscular weakness, which led to discontinuation of study treatment, and grade 3 febrile neutropenia.

Other safety findings The most frequently reported treatment-emergent (all-causality) non-hematologic AEs in patients treated on Schedule 4/2 were typically grade 1 or 2. Common toxicities were generally constitutional (fatigue, pyrexia, mucosal inflammation, anorexia), gastrointestinal (diarrhea, nausea, vomiting, stomatitis), or cutaneous (rash and alopecia).
Grade 3/4 treatment-emergent AEs included neutropenia (6 patients), hypophosphatemia (4 patients), febrile neutropenia (3 patients), fatigue ( 2 patients), and nausea, infection, hemoglobin decrease and hyperglycemia, in 1 patient each (Table 4). At the MTD, 1 patient developed grade 4 febrile neutropenia and began receiving pegfilgrastim on day 41 of cycle 1 (this event was not considered a DLT as it began after day 31 of cycle 1). Serial ECG and MUGA scans were available for 8 and 4 of 10 patients, respectively. No patient treated on Schedule $4 / 2$ experienced LVEF declines by $\geq 20 \%$ to below the lower limit of normal or grade $>1$ increase in QTc interval. One patient on Schedule 4/2 died during the study (disease progression considered not related to study drug). 
Table 3 Patient disposition

\begin{tabular}{|c|c|c|c|}
\hline & \multirow{2}{*}{$\begin{array}{l}\text { Schedule } 4 / 2 \text { dose } \\
\text { levels }^{\text {a }} 0-1(N=10)\end{array}$} & \multicolumn{2}{|c|}{ Schedule $2 / 1$ dose levels ${ }^{\mathrm{a}} 0-3 \mathrm{~b}$} \\
\hline & & $\begin{array}{l}\text { All patients } \\
(N=40)\end{array}$ & $\begin{array}{l}\text { MTD only dose } \\
\text { level } 3 \mathrm{~b}(n=23)\end{array}$ \\
\hline Median cycles started (range) & $2(1-3)$ & $4(1-6)$ & $4(1-6)$ \\
\hline \multicolumn{4}{|c|}{ Treatment interruption for sunitinib, $n(\%)$} \\
\hline Adverse event & $3(30)$ & $11(28)$ & $9(39)$ \\
\hline Other & 0 & 0 & 0 \\
\hline Dose reduction for sunitinib, $n(\%)$ & $1(10)$ & $5(13)$ & $4(17)$ \\
\hline \multicolumn{4}{|c|}{ Reason for treatment discontinuation, $n(\%)$} \\
\hline Adverse event & $6(60)$ & $5(13)$ & $4(17)$ \\
\hline Consent withdrawn & $1(10)$ & $2(5)$ & $1(4)$ \\
\hline Lack of antitumor activity & $2(20)$ & $16(40)$ & $8(35)$ \\
\hline Sponsor decision & 0 & $3^{\mathrm{b}}(8)$ & $1(4)$ \\
\hline Patient completed study per protocol & $1(10)$ & $14(35)$ & $9(39)$ \\
\hline
\end{tabular}

${ }^{a}$ Dose level $0=$ sunitinib $25 \mathrm{mg}+$ docetaxel $60 \mathrm{mg} / \mathrm{m}^{2} \mathrm{q} 21 \mathrm{~d}$ (initial dose level used); dose level $1=$ sunitinib $37.5 \mathrm{mg}+\mathrm{docetaxel} 60 \mathrm{mg} /$ $\mathrm{m}^{2} \mathrm{q} 21 \mathrm{~d}$; dose level 2 = sunitinib $50 \mathrm{mg}+$ docetaxel $60 \mathrm{mg} / \mathrm{m}^{2} \mathrm{q} 21 \mathrm{~d}$; dose level $3 \mathrm{a}=$ sunitinib $50 \mathrm{mg}+$ docetaxel $75 \mathrm{mg} / \mathrm{m}^{2} \mathrm{q} 21 \mathrm{~d} ;$ dose level $3 \mathrm{~b}=$ sunitinib $37.5 \mathrm{mg}+$ docetaxel $75 \mathrm{mg} / \mathrm{m}^{2} \mathrm{q} 21 \mathrm{~d}$

$\mathrm{b}$ These patients were discontinued from this study and enrolled in a different study of single-agent sunitinib. Two patients discontinued docetaxel due to adverse events. One patient was discontinued due to a concomitant illness

Table 4 All-causality grade 3/4 adverse events $(n, \%)$, all cycles and occurring in $\geq 2$ patients across both treatment schedules

GI Gastrointestinal; NOS not otherwise specified

\begin{tabular}{|c|c|c|c|c|}
\hline \multirow[t]{2}{*}{ Adverse event } & \multicolumn{2}{|c|}{ Schedule $4 / 2(N=10)$} & \multicolumn{2}{|c|}{ Schedule $2 / 1(N=40)$} \\
\hline & $\begin{array}{l}\text { Grade } 3 \\
n(\%)\end{array}$ & $\begin{array}{l}\text { Grade } 4 \\
n(\%)\end{array}$ & $\begin{array}{l}\text { Grade } 3 \\
n(\%)\end{array}$ & $\begin{array}{l}\text { Grade } 4 \\
n(\%)\end{array}$ \\
\hline Neutropenia & $1(10.0)$ & $5(50.0)$ & $4(10.0)$ & $20(50.0)$ \\
\hline Fatigue & $2(20.0)$ & 0 & $8(20.0)$ & 0 \\
\hline Febrile neutropenia & $2(20.0)$ & $1(10.0)$ & $1(2.5)$ & $3(7.5)$ \\
\hline Hyperglycemia & $1(10.0)$ & 0 & $4(10.0)$ & 0 \\
\hline Hypophosphatemia & $4(40)$ & 0 & 0 & 0 \\
\hline Leukopenia & 0 & 0 & $3(7.5)$ & $1(2.5)$ \\
\hline Hypokalaemia & 0 & 0 & $3(7.5)$ & 0 \\
\hline Dyspnea & 0 & 0 & $1(2.5)$ & $1(2.5)$ \\
\hline Diarrhea & 0 & 0 & $3(7.5)$ & 0 \\
\hline Hemaglobin decrease & $1(10.0)$ & 0 & $1(2.5)$ & 0 \\
\hline Hypersensitivity & 0 & 0 & $2(5.0)$ & 0 \\
\hline Infection (NOS) & $1(10.0)$ & 0 & $1(2.5)$ & 0 \\
\hline Nausea & $1(10.0)$ & 0 & $1(2.5)$ & 0 \\
\hline Pyrexia & 0 & 0 & $2(5.0)$ & 0 \\
\hline
\end{tabular}

Because the established MTD on Schedule 4/2 (sunitinib $25 \mathrm{mg} /$ day plus docetaxel $60 \mathrm{mg} / \mathrm{m}^{2} \mathrm{q} 21 \mathrm{~d}$ ) was considered sub-optimal for both agents and inconvenient for administration, this schedule was not pursued any further.

\section{Schedule 2/1}

Determination of MTD On Schedule 2/1, 2 of 6 patients experienced a DLT (grade 4 neutropenia, grade 4 febrile neutropenia) on sunitinib $25 \mathrm{mg} /$ day plus docetaxel $60 \mathrm{mg} /$ $\mathrm{m}^{2}$ q21d (dose level 0), the first dose level tested on Schedule 2/1. However, since this regimen was tolerable on Schedule 4/2 (where sunitinib was received for 28 days compared with 14 days on Schedule 2/1), the study was amended to enroll an additional 3 patients at this dose level to further explore the toxicity profile. No further DLTs occurred and dose escalation proceeded. Three patients were treated at each of the next two dose levels (sunitinib $37.5 \mathrm{mg} /$ day plus docetaxel $60 \mathrm{mg} / \mathrm{m}^{2}$ q21d [dose level 1], sunitinib $50 \mathrm{mg} /$ day plus docetaxel $60 \mathrm{mg} / \mathrm{m}^{2} \mathrm{q} 21 \mathrm{~d}$ [dose 
level 2]), and no DLTs were observed. Both patients treated with sunitinib $50 \mathrm{mg}$ plus docetaxel $75 \mathrm{mg} / \mathrm{m}^{2}$ q21d (dose level 3) experienced DLTs (grade 3 febrile neutropenia and grade 4 neutropenia); therefore a lower dose level was tested (dose level 3b: sunitinib $37.5 \mathrm{mg} /$ day plus docetaxel $75 \mathrm{mg} / \mathrm{m}^{2} \mathrm{q} 21 \mathrm{~d}$ ). At this dose level, 1 of 6 patients experienced a DLT (grade 3 gastrointestinal hemorrhage), and sunitinib $37.5 \mathrm{mg} / \mathrm{day}$ on Schedule $2 / 1$ plus docetaxel $75 \mathrm{mg} / \mathrm{m}^{2}$ q21d was determined to be the MTD. Seventeen additional patients were enrolled at Schedule 2/1 MTD to further characterize the safety, tolerability, and antitumor effects of the treatment combination, and to obtain full PK profiles on sufficient patients (a total of 23 patients were enrolled at Schedule 2/1 MTD). Of these 17 additional patients, 1 experienced a DLT (grade 4 febrile neutropenia).

Other safety findings Fatigue (70\%), diarrhea (57\%), and pyrexia (57\%) were the most frequently reported treatment-emergent (all-causality) non-hematologic AEs in patients treated at the MTD on Schedule 2/1. Most of these AEs were mild or moderate in severity (grade 1 or 2 ). The most common grade 3 treatment-emergent non-hematologic AEs in patients treated at the MTD were fatigue (22\%), hyperglycemia (13\%), hypokalemia (13\%), diarrhea, and pyrexia (both 9\%) (Table 5). Grade 4 nonhematologic AEs occurring at the MTD on Schedule 2/1 were hyperuricemia and atrophic vulvovaginitis (both $n=1[4 \%]$ ). There were no notable differences in types and severity of AEs in the MTD group compared with all subjects on Schedule 2/1.

Grade 4 hematologic laboratory abnormalities in the 23 patients treated at the MTD on Schedule 2/1 were neutropenia, $n=15$ (65\%), febrile neutropenia $n=2(9 \%)$, and leukopenia, $n=1$ (4\%). Across all Schedule 2/1 dose levels, neutropenia (any grade) was attributable to sunitinib and to docetaxel in 19/40 (48\%) and 24/40 (60\%) patients, respectively, (in 3 subjects, neutropenia was attributed to both drugs). Across all Schedule $2 / 1$ dose levels, febrile neutropenia of any grade was attributable to sunitinib and to docetaxel in 5/40 (13\%) and 4/40 (10\%) patients, respectively. Overall, 14 patients received granulocytic growth factor support on Schedule 2/1, including $11(48 \%)$ in the MTD cohort; growth factors used most commonly were pegfilgrastim, and filgrastim were given during cycles 2,3 , or 4 of the study treatment. Despite the use of growth factor support, the incidence of grade 3/4 febrile neutropenia was $13 \%$ in the MTD cohort. Erythropoeitic growth factors administered included erythropoietin $(n=3[8 \%]$ and $n=1$ [4\%]), darbepoetin alfa $(n=4[10 \%]$ and $n=4[17 \%])$, and epoetin alfa $(n=2[5 \%]$ and $n=1[4 \%])$ on Schedule 2/1 overall and the MTD cohort, respectively. In addition, 1 patient on the MTD cohort received packed red blood cells.

Of the subjects receiving prophylactic growth factors, 3 $(6 \%)$ on Schedule 2/1 were receiving growth factors (erythropoietin, $n=3$ ) for pre-existing anemia before beginning treatment with sunitinib/docetaxel. Two patients on Schedule 2/1 (6\%) began receiving growth factors during cycle 1: One patient (sunitinib $25 \mathrm{mg}$ plus docetaxel $60 \mathrm{mg}$ / $\mathrm{m}^{2}$ ) began receiving pegfilgrastim on day 12 of cycle 1 , after experiencing grade 4 febrile neutropenia; this event was considered a DLT. The second patient (sunitinib $37.5 \mathrm{mg}$ plus docetaxel $75 \mathrm{mg} / \mathrm{m}^{2}$ ) began pegfilgrastim on day 10 of cycle 1 , after experiencing grade 4 neutropenia; this event was not considered a DLT as it resolved in 4 days.

The subject who experienced the grade 3 DLT of gastrointestinal hemorrhage on the Schedule 2/1 MTD was a 38-year-old white female with neuroendocrine tumor diagnosed 6 years earlier and previously treated with pancreatectomy, splenectomy, external beam radiation to the pancreas, 5-fluorouracil, octreotide, gefitinib, cisplatin/ etoposide, and two experimental study medications. The subject entered the study with liver and lung metastases, pleural effusion, and ascites. On day 13 of cycle 1 ,she was admitted to the hospital and treated for an ileus and discharged the following day. The subject returned to clinic on day 20 of cycle 1 and reported black, tarry stools; endoscopy revealed severe esophagitis, which was treated
Table 5 All-causality adverse events including all grades $(n$, $\%)$ in all cycles and occurring in $\geq 2$ patients (grade $3 / 4$ ) for Schedule $2 / 1$ at the MTD (sunitinib $37.5 \mathrm{mg}+$ docetaxel $\left.75 \mathrm{mg} / \mathrm{m}^{2} \mathrm{q} 21 \mathrm{~d}\right)$

\begin{tabular}{|c|c|c|c|c|}
\hline \multirow[t]{2}{*}{ Adverse event } & \multicolumn{4}{|c|}{ Schedule 2/1 MTD $(N=23)$} \\
\hline & $\begin{array}{l}\text { Grade } 1 \\
n(\%)\end{array}$ & $\begin{array}{l}\text { Grade } 2 \\
n(\%)\end{array}$ & $\begin{array}{l}\text { Grade } 3 \\
n(\%)\end{array}$ & $\begin{array}{l}\text { Grade } 4 \\
n(\%)\end{array}$ \\
\hline Neutropenia & 0 & $2(8.7)$ & 0 & $15(65.2)$ \\
\hline Fatigue & $4(17.4)$ & $7(30.4)$ & $5(21.7)$ & 0 \\
\hline Febrile neutropenia & 0 & 0 & $1(4.3)$ & $2(8.7)$ \\
\hline Hyperglycemia & $1(4.3)$ & $4(17.4)$ & $3(13.0)$ & 0 \\
\hline Leukopenia & 0 & $1(4.3)$ & $1(4.3)$ & $1(4.3)$ \\
\hline Hypokalaemia & 0 & 0 & $3(13.0)$ & 0 \\
\hline Diarrhea & $5(21.7)$ & $6(26.1)$ & $2(8.7)$ & 0 \\
\hline Pyrexia & $7(30.4)$ & $4(17.4)$ & $2(8.7)$ & 0 \\
\hline
\end{tabular}


with esomeprazole and blood transfusion. This DLT resolved with dose delay/reduction of the study drug and gastrointestinal hemorrhage recurred 4 weeks later at grade 1 , resolving without action.

Serial ECGs were available for 25 of 40 patients and MUGA scans were available for 22 of 40 patients, respectively. No patients experienced LVEF declines by $\geq 20 \%$ to below the lower limit of normal or grade $>1$ increase in QTc interval. Hand-foot syndrome occurred in $10 \%$ of patients on Schedule $2 / 1$, with one patient experiencing a grade 3 event. Four patients on Schedule 2/1 died during the study; three deaths were reported during the study, and one was reported after the follow-up period. All deaths were considered to be due to disease progression and were not attributed to the study medication.

Pharmacokinetics Mean sunitinib and docetaxel concentration data showed overlapping profiles during cycles 1 (docetaxel alone) and 2 (docetaxel plus sunitinib) (Fig. 1). These patients were administered sunitinib starting on day 3. Plasma PK parameter values and geometric mean ratios for patients with paired observations for sunitinib, SU12662, total drug, and docetaxel, following multiple dosing with sunitinib alone and with docetaxel, are summarized in Table 6a and b, respectively. For subjects treated on Schedule $2 / 1$ at the MTD, the respective geometric mean ratios (i.e. sunitinib + docetaxel to sunitinib alone) of $\mathrm{C}_{\max }$ and $\mathrm{AUC}_{24}$ were 1.09 and 1.05 for sunitinib, 1.16 and 0.99 for SU12662, and 1.10 and 1.06 for total drug. The mean trough plasma concentration for day 14 of cycle 1 was $43.8 \mathrm{ng} / \mathrm{mL}$ for sunitinib, $16.4 \mathrm{ng} / \mathrm{mL}$ for SU12662, and $60.1 \mathrm{ng} / \mathrm{mL}$ for total drug. The PK parameters for sunitinib $(37.5 \mathrm{mg})$ and docetaxel $\left(60 \mathrm{mg} / \mathrm{m}^{2}\right)$ on Schedules $4 / 2$ dose level 1 and $2 / 1$ dose level $3 b$ in this study are consistent with other studies at this dose level of sunitinib. PK samples for sunitinib were collected at a steady state after 18 or 22 days of treatment on Schedule 4/ 2 compared with at the beginning of each cycle (after 7 days of wash out time when sunitinib level is very low) on Schedule 2/1, and therefore PK parameters differed.

Efficacy assessments Nine patients on Schedule 4/2 were evaluable for efficacy: 4 patients (44\%) achieved stable disease (SD) and 2 patients (22\%) experienced progressive disease (PD). Response data for 3 patients were not evaluable (no post-baseline measurements available).

Thirty-eight patients on Schedule 2/1 were evaluable for efficacy. Three patients (13\%) treated at MTD achieved a partial response (PR) and had the following primary tumor types and characteristics (all had multiple metastases): invasive adenocarcinoma of the breast (67-year-old white female who had prior surgery but no prior radiotherapy or
Fig. 1 Mean a sunitinib and $\mathbf{b}$ docetaxel plasma dose corrected linear and log-linear concentration versus time profiles for patients who received MTD (37.5 mg sunitinib plus $75 \mathrm{mg} / \mathrm{m}^{2}$ docetaxel) on Schedule $2 / 1^{\mathrm{a}}$
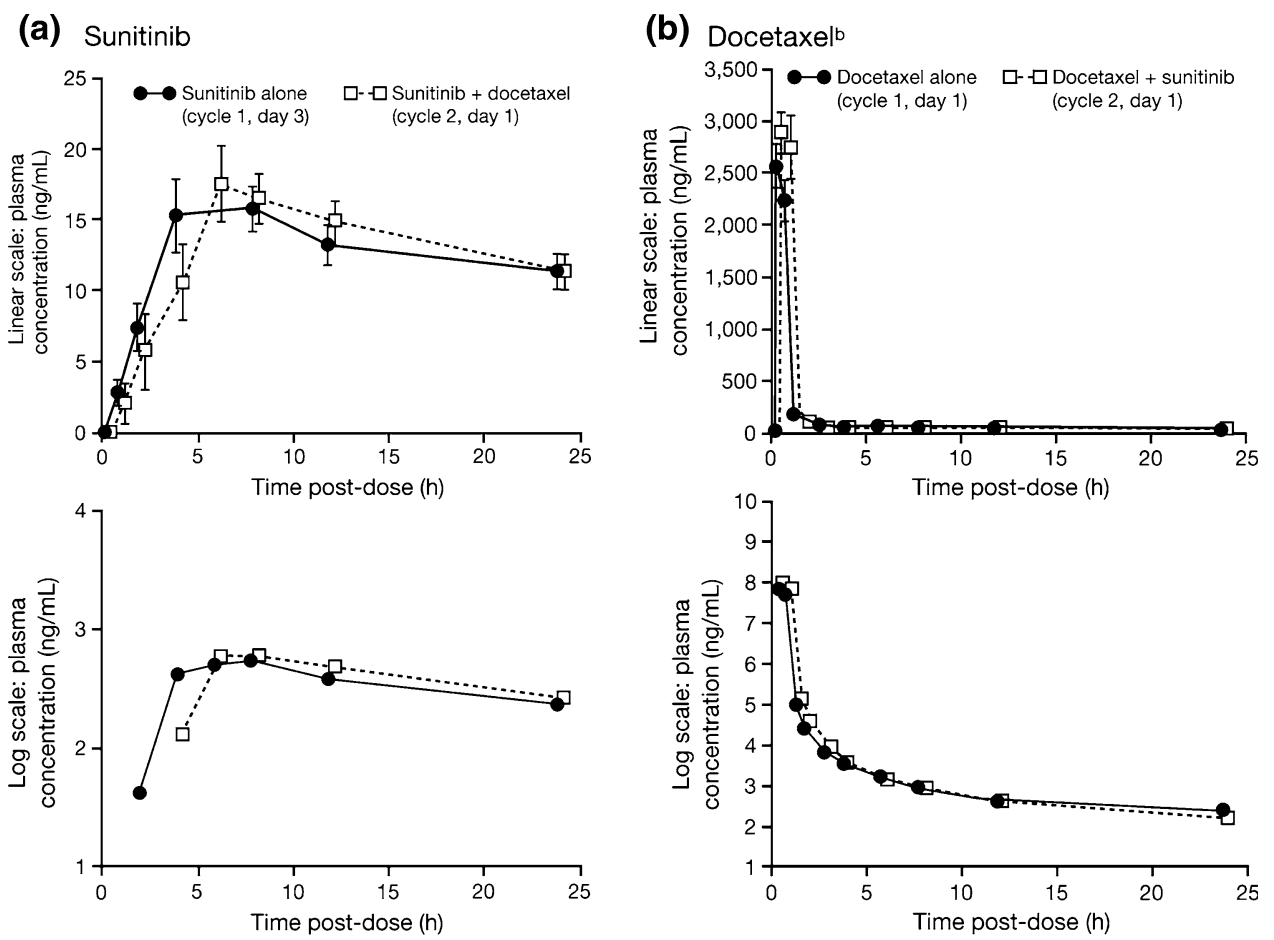

aPatients with paired observations only

bFour patients were excluded due to an error in sample collection; the docetaxel sample collection started at $0.5 \mathrm{~h}$ after the end of infusion instead of $0.5 \mathrm{~h}$ into infusion and therefore $\mathrm{C}_{\max }$ of docetaxel is missing 
Table 6 PK parameters for study drugs (patients with paired observations only)

\begin{tabular}{lll}
\hline $\begin{array}{l}\text { Mean (SD) } \\
\text { sunitinib alone }\end{array}$ & $\begin{array}{l}\text { Mean (SD) } \\
\text { docetaxel + sunitinib }\end{array}$ & $\begin{array}{l}\text { Geometric mean ratio } \\
\text { (combination/drug alone) }\end{array}$ \\
\hline
\end{tabular}

(a) Sunitinib, SU12662, ${ }^{\mathrm{c}}$ and total drug ${ }^{\mathrm{d}}$

Schedule $4 / 2$

Dose level $0, n=3$

Sunitinib

$\begin{array}{lc}\mathrm{AUC}_{0-24}(\mathrm{ng} * \mathrm{~h} / \mathrm{mL}) & 721.2(289.0) \\ C_{\max (\mathrm{ng} / \mathrm{mL})} & 36.4(15.7) \\ T_{\max (\mathrm{a})}^{\mathrm{a}} & 6.0(4.0,6.0)\end{array}$

SU12662

$\mathrm{AUC}_{0-24}(\mathrm{ng} * \mathrm{~h} / \mathrm{mL})$

$C_{\max (\mathrm{ng} / \mathrm{mL})}$

$T_{\max (\mathrm{h})}^{\mathrm{a}}$

Total drug

$$
\mathrm{AUC}_{0-24}(\mathrm{ng} * \mathrm{~h} / \mathrm{mL})
$$

$C_{\max (\mathrm{ng} / \mathrm{mL})}$

$T_{\max (\mathrm{h})}^{\mathrm{a}}$

Schedule $4 / 2$

Dose level $1, n=5$

Sunitinib

$$
\begin{aligned}
& \mathrm{AUC}_{0-24}(\mathrm{ng} * \mathrm{~h} / \mathrm{mL}) \\
& C_{\max (\mathrm{ng} / \mathrm{mL})} \\
& T_{\max }^{\mathrm{a}}(\mathrm{h})
\end{aligned}
$$

SU12662

$\mathrm{AUC}_{0-24}(\mathrm{ng} * \mathrm{~h} / \mathrm{mL})$

$C_{\text {max }}(\mathrm{ng} / \mathrm{mL})$

$T_{\text {max (h) }}^{\mathrm{a}}$

Total drug

$$
\begin{aligned}
& \mathrm{AUC}_{0-24}(\mathrm{ng} * \mathrm{~h} / \mathrm{mL}) \\
& C_{\max (\mathrm{ng} / \mathrm{mL})} \\
& T_{\max (\mathrm{h})}^{\mathrm{a}}
\end{aligned}
$$

Schedule 2/1

Dose level $3 b^{\mathrm{b}}$,

$$
n=10
$$

Sunitinib

$$
\begin{aligned}
& \mathrm{AUC}_{0-24}(\mathrm{ng} * \mathrm{~h} / \mathrm{mL}) \\
& C_{\max (\mathrm{ng} / \mathrm{mL})} \\
& T_{\max (\mathrm{h})}^{\mathrm{a}}
\end{aligned}
$$

SU12662

$\mathrm{AUC}_{0-24}(\mathrm{ng} * \mathrm{~h} / \mathrm{mL})$

$C_{\text {max }}(\mathrm{ng} / \mathrm{mL})$

$T_{\max (\mathrm{h})}^{\mathrm{a}}$

Total drug

$$
\begin{aligned}
& \mathrm{AUC}_{0-24}(\mathrm{ng} * \mathrm{~h} / \mathrm{mL}) \\
& C_{\max (\mathrm{ng} / \mathrm{mL})} \\
& T_{\max (\mathrm{h})}^{\mathrm{a}}
\end{aligned}
$$

294.0 (195.0)

$13.3(8.3)$

$4.0(4.0,12.0)$

$1,015.5$ (478.7)

49.1 (23.8)

$4.0(4.0,6.0)$

$\begin{aligned} 548.0(164.7) & 0.78 \\ 27.8(7.4) & 0.79 \\ 4.0(4.0,4.0) & \text { NA } \\ 299.9(132.7) & 1.10 \\ 14.4(7.2) & 1.14 \\ 4.0(2.0,4.0) & \text { NA } \\ 848.3(288.7) & \\ 42.1(14.2) & 0.86 \\ 4.0(4.0,4.0) & 0.89\end{aligned}$

$4.0(4.0,4.0)$

NA

$\begin{array}{cc}1,020.4(263.9) & 0.88 \\ 51.9(12.9) & 0.87 \\ 4.0(4.0,4.0) & \text { NA } \\ 366.8(137.5) & 1.06 \\ 17.7(7.2) & 1.05 \\ 4.0(1.0,12.0) & \text { NA } \\ 1,387.4(346.7) & \\ 69.5(18.3) & 0.92 \\ 4.0(4.0,4.0) & 0.91 \\ & \text { NA }\end{array}$

$\begin{aligned} 312.9(88.4) & 1.05 \\ 19.7(7.4) & 1.09 \\ 7.0(2.0,12.0) & \mathrm{NA} \\ 62.7(32.4) & 0.99 \\ 4.1(1.9) & 1.16 \\ 7.0(2.0,24.0) & \mathrm{NA} \\ 374.2(103.7) & \\ 23.4(8.9) & 1.06 \\ 8.0(2.0,24.0) & 1.10 \\ & \mathrm{NA}\end{aligned}$


Table 6 continued

\begin{tabular}{|c|c|c|c|}
\hline & $\begin{array}{l}\text { Mean (SD) } \\
\text { sunitinib alone }\end{array}$ & $\begin{array}{l}\text { Mean }(\mathrm{SD}) \\
\text { docetaxel }+ \text { sunitinib }\end{array}$ & $\begin{array}{l}\text { Geometric mean ratio } \\
\text { (combination/drug alone) }\end{array}$ \\
\hline \multicolumn{4}{|c|}{ (b) Docetaxel PK parameters ${ }^{\mathrm{d}}$} \\
\hline \multicolumn{4}{|l|}{ Schedule $4 / 2$} \\
\hline \multicolumn{4}{|l|}{ Dose level $1, n=5$} \\
\hline \multicolumn{4}{|l|}{ Docetaxel } \\
\hline $\mathrm{AUC}_{\text {last }(\mathrm{ng} * \mathrm{~h} / \mathrm{mL})}$ & $2,290.4(596.1)$ & $3,415.4(1,102.8)$ & 1.47 \\
\hline $\mathrm{AUC}_{\mathrm{inf}(\mathrm{ng} * \mathrm{~h} / \mathrm{mL})}$ & $2,552.7(649.4)$ & $3,692.8(1,099.8)$ & 1.43 \\
\hline$C_{\max (\mathrm{ng} / \mathrm{mL})}$ & $2,100.0(571.9)$ & 3,098.0 (984.2) & 1.46 \\
\hline$t_{1 / 2(\mathrm{~h})}$ & $19.6(10.6)$ & $21.3(7.4)$ & NA \\
\hline$T_{\max (\mathrm{h})}^{\mathrm{a}}$ & $0.5(0.5,1.0)$ & $0.5(0.4,1.0)$ & NA \\
\hline \multicolumn{4}{|l|}{ Schedule $2 / 1$} \\
\hline \multicolumn{4}{|l|}{ Dose level $3 b, n=8$} \\
\hline \multicolumn{4}{|c|}{ Docetaxel } \\
\hline $\mathrm{AUC}_{\text {last }(\mathrm{ng} * \mathrm{~h} / \mathrm{mL})}$ & $2,712.5(731.9)$ & $3,056.5(303.7)$ & 1.16 \\
\hline $\mathrm{AUC}_{\mathrm{inf}(\mathrm{ng} * \mathrm{~h} / \mathrm{mL})}$ & $2,961.5(766.6)$ & $3,235.9(298.5)$ & 1.12 \\
\hline$C_{\max (\mathrm{ng} / \mathrm{mL})}$ & $2,581.3(535.6)$ & $3,180.0(495.5)$ & 1.24 \\
\hline$t_{1 / 2(\mathrm{~h})}$ & $15.7(9.9)$ & $17.7(7.9)$ & NA \\
\hline$T_{\max (\mathrm{h})}^{\mathrm{a}}$ & $0.6(0.5,1.0)$ & $0.8(0.5,1.0)$ & NA \\
\hline \multicolumn{4}{|c|}{ Dose levels of sunitinib and docetaxel are detailed in Table 1} \\
\hline \multicolumn{4}{|c|}{${ }^{\mathrm{a}}$ For $\mathrm{T}_{\max }$, median and range are reported } \\
\hline \multicolumn{4}{|c|}{ b $2 / 1 \mathrm{MTD}=$ sunitinib $37.5 \mathrm{mg}+$ docetaxel $75 \mathrm{mg} / \mathrm{m}^{2} \mathrm{q} 21 \mathrm{~d}$} \\
\hline \multicolumn{4}{|c|}{ c SU12662 is the primary metabolite of sunitinib } \\
\hline \multicolumn{4}{|c|}{$\begin{array}{l}\text { d Full PK profiles for sunitinib and SU12662 were obtained on days } 18 \text { and } 22 \text { on Schedule } 4 / 2 \text { and on day } 3 \text { of cycle } 1 \text {, and day } 1 \text { of cycle } 2 \text { on } \\
\text { Schedule } 2 / 1 \text {. PK profiles for docetaxel were obtained on days } 1 \text { and } 22 \text { of cycle } 1 \text { on Schedule } 4 / 2 \text { and on day } 1 \text { of cycles } 1 \text { and } 2 \text { on Schedule } 2 / 1\end{array}$} \\
\hline
\end{tabular}

systemic therapy), small cell lung cancer (63-year-old white female who had prior surgery and received carboplatin/etoposide and oxaliplatin/irinotecan as previous systemic therapies), and NSCLC (62-year-old white female who received carboplatin/gemcitabine as previous systemic therapy). SD ( $\geq 6$ weeks) was observed in $12(32 \%)$ patients treated on Schedule 2/1, including $6(43 \%)$ treated at the MTD. PD was observed in 11 (29\%) patients on Schedule $2 / 1$, including $7(32 \%)$ of the patients treated at MTD. Post-baseline measurements were not available for 5 patients, and response data were not evaluable for 7 patients.

\section{Discussion}

For many patients with solid tumors refractory to chemotherapy, therapeutic options are limited. Newer targeted therapies, which may be given in combination with chemotherapy, may offer a potential treatment approach [4, 19, 24, 25].

The primary objective of this phase I dose-finding study was to assess the MTD and overall safety of sunitinib administered on Schedules $4 / 2$ or $2 / 1$ in combination with docetaxel for the treatment of subjects with advanced solid tumors, including some who were heavily pre-treated and/ or had multiple metastases. This phase I study determined the MTD as sunitinib $25 \mathrm{mg} /$ day on Schedule $4 / 2$ plus docetaxel $60 \mathrm{mg} / \mathrm{m}^{2} \mathrm{q} 21 \mathrm{~d}(n=4)$. The MTD was determined as sunitinib $37.5 \mathrm{mg} /$ day plus docetaxel $75 \mathrm{mg} / \mathrm{m}^{2}$ q21d $(n=23)$ on Schedule 2/1.

The safety profile at MTD on Schedule 2/1 (sunitinib $37.5 \mathrm{mg} /$ day plus docetaxel $75 \mathrm{mg} / \mathrm{m}^{2} \mathrm{q} 21 \mathrm{~d}$ ) in this population of heavily pre-treated patients was acceptable with aggressive management of hematologic toxicities. Most toxicities were mild or moderate in severity (grade 1 or 2) and similar in type to those previously reported with sunitinib and with docetaxel in patients with advanced solid tumors [7, 19, 26]. The most common non-hematologic toxicities were fatigue, diarrhea, and pyrexia. The observed safety profile was similar to that reported with this treatment regimen (Schedule 2/1 sunitinib $37.5 \mathrm{mg} /$ day, docetaxel $75 \mathrm{mg} / \mathrm{m}^{2} \mathrm{q} 21 \mathrm{~d}$ ) in an exploratory analysis of patients with breast cancer [27], as well as that reported following administration of docetaxel [7]. In this breast cancer study by Gianni et al. [27] the most commonly observed AE was 
severe neutropenia, which occurred at least once in all patients. Neutropenia is commonly associated with docetaxel monotherapy; grade 3/4 neutropenia has been reported in 54-84\% of patients in phase III trials of breast cancer and NSCLC [28, 29]. The incidence of grade 3/4 febrile neutropenia observed in this trial, although higher than reported with single-agent docetaxel [28, 29], was manageable with growth factor support. The sunitinib-docetaxel treatment combination appeared to be associated with more common and more severe hematologic toxicity than is typically observed with docetaxel or sunitinib alone [7, 30]. In this phase I trial, $13 \%$ of patients treated at Schedule 2/1 MTD experienced febrile neutropenia despite the use of granulocytic growth factor support in $48 \%$ of patients. It is noteworthy that use of granulocytic growth factor support was substantially lower with single-agent docetaxel (17.9\%) compared with this study of sunitinib combined with docetaxel [29].Given the limited number of patients in this study, it is difficult to identify the effects of the possible factors exacerbating neutropenia. While it is probable that the neutropenia observed in this study may be related to the heavily pre-treated nature of our patients and/or to sunitinib treatment itself, determining a direct causality is not possible. The manageability of the hematologic toxicities with granulocytic growth factor support in this trial contrasts some previous studies. For example, the phase III trial evaluating sorafenib, carboplatin, and paclitaxel efficacy in NSCLC (ESCAPE) was terminated early due to increased risk of mortality and toxicities, including higher rates of grade 3/4 thrombocytopenia (14 vs. $6 \%$ ) and febrile neutropenia $(5 \%$ vs. $<3 \%)$ in patients treated with sorafenib compared with chemotherapy alone [31]. Similarly, the phase II/III trial of cediranib ( $30 \mathrm{mg} /$ day or $45 \mathrm{mg} /$ day), carboplatin, and paclitaxel in patients with NSCLC was terminated due to increased toxicities in the investigative arm [32]. While c-Kit and FLT are important in hematopoiesis and may be key players in myelosuppression, their potential off-target inhibition by sunitinib was not evaluated in this study.

No patient experienced cardiac abnormalities, including LVEF declines by $\geq 20 \%$ or to below the lower limit of normal, suggesting that the combination does not lead to an excessive risk for cardiac toxicity. Mean sunitinib and docetaxel concentration data show overlapping PK profiles during cycle 1 (docetaxel alone) and cycle 2 (docetaxel plus sunitinib). Changes in PK parameters for docetaxel, sunitinib, SU12662, and total drug at MTD on Schedule 2/ $1\left(37.5 \mathrm{mg} /\right.$ day sunitinib with $75 \mathrm{mg} / \mathrm{m}^{2}$ docetaxel) are not considered clinically relevant and indicate no PK drugdrug interactions between sunitinib and docetaxel.

In summary, experience from our phase I trial demonstrated that although $17 \%$ of patients treated at MTD required sunitinib dose reductions and 13\% developed grade 3 or 4 febrile neutropenia, the heavily pre-treated patients with advanced solid malignancies tolerated sunitinib on Schedule 2/1 in combination with docetaxel at relevant doses of both agents. Therefore, the use of growth factor support and the incidence of febrile neutropenia will be evaluated closely in ongoing clinical trials of this treatment combination to characterize more fully the hematologic tolerability of this regimen. Ongoing clinical trials include a phase III breast cancer trial comparing $37.5 \mathrm{mg}$ sunitinib on Schedule 2/1 plus docetaxel $75 \mathrm{mg} / \mathrm{m}^{2}$ q21d with docetaxel $100 \mathrm{mg} / \mathrm{m}^{2} \mathrm{q} 21 \mathrm{~d}$ alone, and a phase I/II trial of sunitinib $(12.5,37.5$, and $50 \mathrm{mg}$ on Schedule 2/1) in combination with docetaxel $\left(60\right.$ and $\left.75 \mathrm{mg} / \mathrm{m}^{2}\right)$ and prednisone $5 \mathrm{mg}$ twice daily for the first-line treatment of metastatic castrate-resistant prostate cancer. In the phase I trial reported here, there were no clinically significant drugdrug interactions noted with either schedule, and although efficacy was not a primary endpoint of this trial, antitumor data were suggestive of potential clinical benefit.

Acknowledgments We thank Tanya Boutros for her contribution to the analytical part of this study, and Dr. Shem Patyna for reviewing and contributing to the intellectual content of this manuscript. Editorial assistance was provided by ACUMED ${ }^{\circledR}$ (Tytherington, UK) and was funded by Pfizer Inc. The study was sponsored by Pfizer Inc.

Open Access This article is distributed under the terms of the Creative Commons Attribution Noncommercial License which permits any noncommercial use, distribution, and reproduction in any medium, provided the original author(s) and source are credited.

\section{References}

1. Hasumi Y, Klosowska-Wardega A, Furuhashi M, Ostman A, Heldin CH, Hellberg C (2007) Identification of a subset of pericytes that respond to combination therapy targeting PDGF and VEGF signaling. Int J Cancer 121:2606-2614

2. Potapova O, Laird AD, Nannini MA et al (2006) Contribution of individual targets to the antitumor efficacy of the multitargeted receptor tyrosine kinase inhibitor SU11248. Mol Cancer Ther 5:1280-1289

3. Shikada Y, Yonemitsu Y, Koga T et al (2005) Platelet-derived growth factor-AA is an essential and autocrine regulator of vascular endothelial growth factor expression in non-small cell lung carcinomas. Cancer Res 65:7241-7248

4. Sandler A, Gray R, Perry MC et al (2006) Paclitaxel-carboplatin alone or with bevacizumab for non-small-cell lung cancer. $\mathrm{N}$ Engl J Med 355:2542-2550

5. Manegold C, Von Pawel J, Zatloukal P et al. (2008) BO17704 (AVAIL): a phase III randomised study of first-line bevacizumab combined with cisplatin/gemcitabine (CG) in patients (pts) with advanced or recurrent non-squamous, non-small cell lung cancer (NSCLC). Ann Oncol 19:viii1 (Abstract LBA1)

6. Montero A, Fossella F, Hortobagyi G, Valero V (2005) Docetaxel for treatment of solid tumours: a systematic review of clinical data. Lancet Oncol 6:229-239

7. Sanofi-aventis (2007) Taxotere (docetaxel) Prescribing Information. Sanofi-aventis, New York 
8. Demetri GD, van Oosterom AT, Garrett CR et al (2006) Efficacy and safety of sunitinib in patients with advanced gastrointestinal stromal tumour after failure of imatinib: a randomised controlled trial. Lancet 368:1329-1338

9. Motzer RJ, Michaelson MD, Redman BG et al (2006) Activity of SU11248, a multitargeted inhibitor of vascular endothelial growth factor receptor and platelet-derived growth factor receptor, in patients with metastatic renal cell carcinoma. J Clin Oncol 24:16-24

10. Motzer RJ, Hutson TE, Tomczak P et al (2007) Sunitinib versus interferon alfa in metastatic renal-cell carcinoma. N Engl J Med 356:115-124

11. Abrams TJ, Lee LB, Murray LJ, Pryer NK, Cherrington JM (2003) SU11248 inhibits KIT and platelet-derived growth factor receptor beta in preclinical models of human small cell lung cancer. Mol Cancer Ther 2:471-478

12. Kim DW, Jo YS, Jung HS et al (2006) An orally administered multitarget tyrosine kinase inhibitor, SU11248, is a novel potent inhibitor of thyroid oncogenic RET/papillary thyroid cancer kinases. J Clin Endocrinol Metab 91:4070-4076

13. Mendel DB, Laird AD, Xin X et al (2003) In vivo antitumor activity of SU11248, a novel tyrosine kinase inhibitor targeting vascular endothelial growth factor and platelet-derived growth factor receptors: determination of a pharmacokinetic/pharmacodynamic relationship. Clin Cancer Res 9:327-337

14. Murray LJ, Abrams TJ, Long KR et al (2003) SU11248 inhibits tumor growth and CSF-1R-dependent osteolysis in an experimental breast cancer bone metastasis model. Clin Exp Metastasis 20:757-766

15. O'Farrell AM, Abrams TJ, Yuen HA et al (2003) SU11248 is a novel FLT3 tyrosine kinase inhibitor with potent activity in vitro and in vivo. Blood 101:3597-3605

16. Pfizer Inc (2008) Data on file

17. Kulke M, Lenz HJ, Meropol N et al (2008) Activity of Sunitinib in patients with advanced neuroendocrine tumors. J Clin Oncol 26:3403-3410

18. Burstein HJ, Elias AD, Rugo HS et al (2008) Phase II study of sunitinib malate, an oral multitargeted tyrosine kinase inhibitor, in patients with metastatic breast cancer previously treated with an anthracycline and a taxane. J Clin Oncol 26:1810-1816

19. Socinski MA, Novello S, Brahmer JR et al (2008) Multicenter, phase II trial of sunitinib in previously treated, advanced nonsmall-cell lung cancer. J Clin Oncol 26:650-656

20. Faivre S, Delbaldo C, Vera K et al (2006) Safety, pharmacokinetic, and antitumor activity of SU11248, a novel oral multitarget tyrosine kinase inhibitor, in patients with cancer. J Clin Oncol 24:25-35

21. Abrams TJ, Murray LJ, Pesenti E et al (2003) Preclinical evaluation of the tyrosine kinase inhibitor SU11248 as a single agent and in combination with "standard of care" therapeutic agents for the treatment of breast cancer. Mol Cancer Ther 2:1011-1021

22. Christensen JG, Hall C, Hollister BA (2008) Antitumor efficacy of sunitinib malate in concurrent and sequential combinations with standard chemotherapeutic agents in non-small cell lung cancer (NSCLC) nonclinical models. Proceedings of the 99th annual meeting of the American association for cancer research

23. Therasse P, Arbuck SG, Eisenhauer EA et al (2000) New guidelines to evaluate the response to treatment in solid tumors. $\mathrm{J}$ Natl Cancer Inst 92:205-216

24. Yang JC, Haworth L, Sherry RM et al (2003) A randomized trial of bevacizumab, an anti-vascular endothelial growth factor antibody, for metastatic renal cancer. N Engl J Med 349:427-434

25. Schoffski P, Dumez H, Clement P et al (2006) Emerging role of tyrosine kinase inhibitors in the treatment of advanced renal cell cancer: a review. Ann Oncol 17:1185-1196

26. SUTENT (2008) (Sunitinib malate) prescribing information. New York, NY

27. Gianni L, Cardoso F, Mariani G, Isaksson-Friman E, BesseHammer T, Vigano L, Verkh L, Rossi, C, Giorgetti C, Bergh J (2007) Exploratory evaluation of a sequential administration of docetaxel and sunitinib in women with advanced breast cancer. Br Cancer Res Treat 106 (Suppl. 1):S273 (Abstract 6079)

28. Fossella FV, DeVore R, Kerr RN et al (2000) Randomized phase III trial of docetaxel versus vinorelbine or ifosfamide in patients with advanced non-small-cell lung cancer previously treated with platinum-containing chemotherapy regimens. The TAX 320 NonSmall Cell Lung Cancer Study Group. J Clin Oncol 18:23542362

29. Harvey V, Mouridsen H, Semiglazov V et al (2006) Phase III trial comparing three doses of docetaxel for second-line treatment of advanced breast cancer. J Clin Oncol 24:4963-4970

30. Hanna N, Shepherd FA, Fossella FV et al (2004) Randomized phase III trial of pemetrexed versus docetaxel in patients with non-small-cell lung cancer previously treated with chemotherapy. J Clin Oncol 22:1589-1597

31. Scagliotti G, Von Pawel J, Reck M, Cupit L, Cihon F, DiMatteo S, O'Leary, J, Hanna N (2008) Sorafenib plus carboplatin/paclitaxel in chemonaive patients with stage IIIb-IV NSCLC: interim analysis results form the phase III, randomized, double-blind, placebo-controlled, ESCAPE (Evaluation of Sorafenib, CArboplatin and Paclitaxel Efficacy in NSCLC) trial

32. Laurie SA, Arnold A, Shepherd FA, Dediu M, Ciuleanu T, Fenton D, Zukin M, Goss G, Ding K, Seymour L (2008) National Cancer Institute of Canada clinical trials group study BR.24, a randomized placebo controlled phase II trial of cediranib (CED) plus carboplatin _ paclitaxel (C_P) in advanced non-small cell lung cancer of any histology: further analyses. J Thorac Oncol 3(11 (Supplement 4)):S262 